\title{
Knowledge and Attitude towards Safe Abortion among Undergraduate Students in Jana Bhawana Campus, Lalitpur, Nepal
}

\author{
Nirmala Ghimire ${ }^{1}$, Manju Nepal ${ }^{2}$, Niran Shrestha ${ }^{3}$, Roshani Khatry $^{4}$ \\ ${ }^{1,2,3,4}$ Assistant Professor, Patan Academy of Health Sciences, School of Nursing and Midwifery, Nepal \\ Corresponding Author: Nirmala Ghimire
}

\begin{abstract}
Background: Unsafe abortion is one of the health issues of the reproductive age women. In spite of abortion legalization, woman's access to safe abortion is based on the knowledge related to safe abortion. Knowledge is essential part which equips women to get services and prevent from complications of unsafe abortion.

Materials and methods: A descriptive cross sectional study was conducted with the objective to identify the knowledge and attitude on safe abortion among bachelor level student. Non probability total enumerative sampling technique was used to select the sample. Total of 310 respondents were included in the study. The structured pretested questionnaire was used to collect data. Pearson chisquare was used to find out the association between demographic variables and knowledge on safe abortion.

Result: The result of the study showed that among the respondents majority $247(79.7 \%)$ were $\geq 20$ years of age with mean age 21.4 years with SD 1.9. More than half 173(55.8) of respondents were female. Majority 193(62.3\%) of the respondents had fair knowledge and nearly half of the respondents $154(49.7 \%)$ had positive attitude regarding safe abortion. Respondents' knowledge on safe abortion were not significantly associated with their age, gender, marital status, ethnicity, type of family, area of residence and living arrangement.

Conclusion: Despite having fair level of knowledge among majority of respondents, it is seen that half of the respondents had negative attitude towards safe abortion. This shows that there is a need for educational intervention among undergraduate students in order to change their attitude.
\end{abstract}

Key words: Attitude, Knowledge, Safe Abortion, Undergraduate Students

\section{INTRODUCTION}

Abortion is considered safe when it is performed in accordance with WHO guidelines and standards, performed by a trained person that is appropriate to the pregnancy duration. Such abortions can be done using tablets (medical abortion) or a simple outpatient procedure. ${ }^{[1]}$

Between 2010-2014, approximately 56 million induced (safe and unsafe) abortions occurred worldwide each year. There were 35 induced abortions per 1000 women aged between 15-44 years. Twenty five percent of all pregnancies ended in an induced abortion. The rate of abortions was higher in developing regions than in developed regions. Among 25 million unsafe abortions, 8 million were carried out in the least- safe or dangerous conditions. Over half of all estimated unsafe abortions globally were in Asia. ${ }^{[2]}$ A nationally representative sample of the Nepal Demographic and Health Survey 2011 were studied among 2395 women who had ever had a terminated pregnancy. The result of the study revealed that five-year prevalence of abortion was $21.1 \%$ among women of reproductive age who ever had a terminated 
pregnancy and $16.0 \%$ of total abortions were unsafe. ${ }^{[3]}$

According to Nepal Demographic Health survey 2016 revealed that four in ten women knew abortion is legal in Nepal. Among these women, 29\% knew abortion is allowed for termination of pregnancies of up to 18 weeks in the case of rape or incest and $23 \%$ know abortion is allowable up to 12 weeks gestation for any women $(23 \%){ }^{[4]}$

Unsafe abortion is a commonly neglected reproductive health care problem in developing countries, yet it poses a serious threat to the health of millions of women during their reproductive lives. Until unsafe abortion and its consequences are eliminated, complications from unsafe abortion will remain a major cause of maternal mortality and morbidity. ${ }^{[5]}$

Youth are facing many sexual and reproductive health issues. Bachelor level student especially female students are vulnerable group and may face problem of teen age pregnancy, unsafe abortion and STIs. For the betterment of maternal health, youth participation is crucial in improving the reproductive health as they become the future parent. They can create awareness and make others utilize safe abortion services when they are equipped with knowledge. Many literatures showed knowledge and practice regarding safe abortion are limited among women. Therefore, this study was carried out to assess knowledge and attitude toward safe abortion among undergraduate students.

\section{MATERIALS AND METHODS}

This is a descriptive cross-sectional research study carried out among undergraduate students in Jana Bhawana Campus, Godavari Municipality, Lalitpur. The college is situated in urban area within Kathmandu valley but students are coming from different remote parts of the country. Total number of bachelor level students studying in bachelor first, second, third and fourth year were 310 in the academic year 2020-21. All undergraduate male and female students were study population.
Students who were critically ill and those students in field work during data collection were excluded.

Data collection period was January 1 to 30,2021 . For data collection a pretested, structured, self-administered questionnaires were used. The questionnaire consisted of socio-demographic information, knowledge and attitude related items on safe abortion. The study instrument was prepared in English and translated into Nepali language. Finally, Nepali version questionnaire was used for data collection. The content validity of study instrument in terms of the adequacy and appropriateness of the content was established by consulting subject experts. Students were kept in their class room respectively maintaining distance and adopting safety measures due to COVID 19 pandemic situation. The respondents were provided 20-25 minutes time for completing the questionnaire.

The sample size was determined using a formula as given below

Sample size $(\mathrm{n})=\frac{Z^{2} p q}{e^{2}}$

The assumptions used for computing sample size are $95 \%$ confidence interval, 5 $\%$ margin of error, and prevalence of knowledge about safe abortion at $80 \%$. ${ }^{[6]}$ Non-response rate of $10 \%$ were considered and sample size was calculated to be 271 . However, total population of the study is 310. Therefore, I had recruited all students utilizing total enumerative sampling technique. Therefore, final sample size was 310 students.

Ethical approval was obtained from Nepal Health Research Council. Then, formal permission was taken from Jana Bhawana Campus. The objective of the study was explained to the students as well as informed written consent was taken from each respondent before data collection. Participants were assured about confidentiality of the information obtained from them that was used only for study purpose and provided information was maintained by omitting personal identifiers. 
Respondents' knowledge on safe abortion calculated out of 23 score. Each correct response assigned ' 1 ' and ' 0 ' for wrong response. Respondents were categorized based on their overall knowledge scores; good knowledge, fair knowledge and poor knowledge. [6] Respondents' attitude was measured out of 10 specific questions. The response options were given a value ranging from one to five scales (Likert Scale). The total attitude score was 50 and 5 questions are positive and 5 questions are negative. For the positive statement 1, 2, 7, 8, 9, scoring will be providing a value ranging from one to five i.e. strongly agree $=5$, agree $=4$, uncertain $=3$, strongly disagree $=2$ and disagree $=1$; whereas for the negative statement $3,4,5$, 6,10 the direction was reversed due to the nature of the questions, which is strongly agree $=1$, agree $=2$, uncertain $=3$, strongly disagree $=4$ and disagree $=5$ based on the respondent's response. After calculating a score of each respondent for the 10 statement, a mean score of the total respondents will be taken as cut offs of value. Attitude of the respondent was categorized based on mean value. The respondents obtained score equals to or greater than mean was considered as having positive attitude and those with less than the mean score was considered as having negative attitude. ${ }^{[7]}$

The collected questionnaires were checked manually for its accuracy and completeness. Then data was coded, labeled, verified, categorized and entered into entered to SPSS version 16 for analysis. The data was analyzed by using descriptive statistics like frequency, percentage, mean and standard deviation. Chi-square test was performed as inferential statistics.

\section{RESULT}

Total of 310 respondents age ranges from 18-25 years, majority 247(79.7\%) had $\geq 20$ years of age with a mean age of $21.4 \pm$ 1.9 years. More than half 173(55.8) of respondents were female. Nearly one third $100(32.3 \%)$ respondents were studying in first year level. Most of the respondents $274(88.4 \%)$ were unmarried. In relation to the ethnicity of the respondents, more than half of respondents $168(54.2 \%)$ belongs to Brahin/Chhetri caste, more than half $(61.0 \%)$ lived in single family. One hundred and sixty $(51.6 \%)$ of respondents permanent residence was urban area and most of the respondents $(85.8 \%)$ living with their family member, Table 1.

Table 1 Socio-demographic characteristics of respondents (N=310)

\begin{tabular}{|l|l|l|}
\hline Characteristics & Frequency & Percent \\
\hline Age in years & 63 & \\
\hline$>20$ years & 247 & 20.3 \\
\hline$\geq 20$ years & & 79.7 \\
\hline Mean age \pm SD 21.4 $\pm \mathbf{1 . 9}$ & & \\
\hline Gender & 173 & 55.8 \\
\hline Female & 137 & 44.2 \\
\hline Male & & \\
\hline Year of study & 100 & 32.3 \\
\hline First year & 75 & 24.2 \\
\hline Second year & 72 & 23.2 \\
\hline Third year & 63 & 20.3 \\
\hline Fourth year & & \\
\hline Marital status & 274 & 88.4 \\
\hline Unmarried & 36 & 11.6 \\
\hline Married & & \\
\hline Ethnicity & 168 & 54.2 \\
\hline Brahmin/Chhetri & 131 & 42.3 \\
\hline Janajati & 6 & 1.9 \\
\hline Dalit & 5 & 1.6 \\
\hline Teraibasi & & \\
\hline Type of family & 189 & 61.0 \\
\hline Single & 121 & 39.0 \\
\hline Joint & & \\
\hline Area of permanent residence & 160 & 51.6 \\
\hline Urban & 150 & 48.4 \\
\hline Rural & & 85.8 \\
\hline Living arrangement & 266 & 14.2 \\
\hline With family member & 44 & \\
\hline With friends/alone & & \\
\hline & & \\
\hline
\end{tabular}

Majority 230(74.2\%) of the respondents correctly answered the meaning of safe abortion as within legal condition performed by trained health worker. Likewise, all the respondents said safe abortion services is necessary to reproductive age women. While asking about importance of safe abortion, majority $204(65.8 \%)$ reported that it is necessary to save the life of mother. When asked about the legal condition of safe abortion in Nepal, majority 270(87.1) stated that abortion is legal in Nepal. Among respondents, more than half $(61.3 \%)$ respondents correctly responded that safe abortion is legally permitted up to 12 weeks of all pregnancy. 
Nirmala Ghimire et.al. Knowledge and attitude towards safe abortion among undergraduate students in Jana Bhawana Campus, Lalitpur, Nepal.

regarding the special condition that are allowed for termination of pregnancy following safe abortion, 195(62.9\%) of the respondents responded that life of woman and fetus threatened. The study further revealed that among respondents all mentioned safe abortion service is available in Nepal. When asked about places to perform safe abortion, majority $261(84.2 \%)$ answered that hospitals are the places for providing safe abortion. Similarly, while performing safe abortion, majority $269(86.8 \%)$ mentioned trained health worker should be required to carry out safe abortion. About asking the method of safe abortion, 192(61.9\%) said medicine can be used to perform safe abortion. Among respondents all knew at least one problem of unsafe abortion, 228(73.5\%), 198(63.9\%), $162(52.3 \%)$ and $31.9 \%)$ respondents answered bleeding, death, infertility and infection as respectively, Table 2 .

More than half $180(58.1 \%)$ strongly agreed that unsafe abortion consider as serious health problems in Nepal. Nearly half of the respondents $129(41.6 \%)$ strongly disagreed the statement a woman should always have the right to have an abortion in case of an unwanted pregnancy. Regarding the consent, $152(49.0 \%)$ of respondent strongly disagree with statement a woman needs to have her partner or spouse's consent to have an abortion. Nearly half $131(42.3 \%)$ of respondents disagreed that family planning methods prevents unwanted pregnancy, Table 3.
Table 2: Knowledge on safe abortion $(\mathrm{N}=310)$

\begin{tabular}{|c|c|c|}
\hline Characteristics & Frequency & Percent \\
\hline \multicolumn{3}{|l|}{ Meaning of safe abortion } \\
\hline $\begin{array}{l}\text { Within legal condition performed by } \\
\text { trained health worker }\end{array}$ & 230 & 74.2 \\
\hline $\begin{array}{l}\text { Mutual understanding among couple } \\
\text { for abortion }\end{array}$ & 42 & 13.5 \\
\hline No harm after carried out abortion & 38 & 12.3 \\
\hline \multicolumn{3}{|l|}{ Important of safe abortion* } \\
\hline To safe life of mother & 204 & 65.8 \\
\hline $\begin{array}{lll}\begin{array}{l}\text { To prevent } \\
\text { pregnancy }\end{array} & \text { from } & \text { unwanted } \\
\end{array}$ & 187 & 60.3 \\
\hline $\begin{array}{l}\text { Pregnancy as a result of rape or } \\
\text { incest }\end{array}$ & 93 & 30.0 \\
\hline \multicolumn{3}{|l|}{ Abortion legal in Nepal } \\
\hline Yes & 270 & 87.1 \\
\hline No & 40 & 12.9 \\
\hline \multicolumn{3}{|c|}{ If yes legally preferable time $(\mathrm{N}=270)$} \\
\hline Up to12 weeks of pregnancy & 190 & 61.3 \\
\hline At any time of pregnancy & 36 & 11.6 \\
\hline Up to 22 weeks of pregnancy & 29 & 9.4 \\
\hline Up to 28 weeks of pregnancy & 15 & 4.8 \\
\hline \multicolumn{3}{|c|}{$\begin{array}{l}\text { Conditions allowed for safe abortion in Nepal* } \\
(\mathrm{N}=270)\end{array}$} \\
\hline Woman or fetus life are threatened & 195 & 62.9 \\
\hline $\begin{array}{l}\text { Pregnancy is resulted from incest or } \\
\text { rape }\end{array}$ & 163 & 52.6 \\
\hline $\begin{array}{l}\text { Woman has physical mental } \\
\text { disabilities }\end{array}$ & 136 & 43.9 \\
\hline Fetus has severe abnormalities & 111 & 35.8 \\
\hline \multicolumn{3}{|l|}{ Places for safe abortion* } \\
\hline Government authorized hospitals & 261 & 84.2 \\
\hline Marie stopes centers & 76 & 24.5 \\
\hline Medical centers/clinic & 71 & 22.9 \\
\hline $\begin{array}{l}\text { Primary health care centers/Health } \\
\text { posts }\end{array}$ & 67 & 21.6 \\
\hline \multicolumn{3}{|l|}{ Health service provider } \\
\hline Trained health worker & 269 & 86.8 \\
\hline Any health worker & 41 & 13.2 \\
\hline \multicolumn{3}{|l|}{ Methods used for safe abortion* } \\
\hline Using medicine & 192 & 61.9 \\
\hline Using instrument & 181 & 58.4 \\
\hline \multicolumn{3}{|c|}{ Problems can arise from unsafe abortion* } \\
\hline Bleeding & 228 & 73.5 \\
\hline Death & 198 & 63.9 \\
\hline Infertility & 162 & 52.3 \\
\hline Infection & 99 & 31.9 \\
\hline
\end{tabular}

Table 3: Respondents' attitude on safe abortion

\begin{tabular}{|l|l|l|l|l|l|l|}
\hline SN & Statements & $\begin{array}{l}\text { Strongly } \\
\text { agree }\end{array}$ & Agree & Uncertain & Disagree & $\begin{array}{l}\text { Strongly } \\
\text { disagree }\end{array}$ \\
\hline 1 & $\begin{array}{l}\text { Unsafe abortion consider as serious health problem in } \\
\text { Nepal. }\end{array}$ & $180(58.1 \%)$ & $106(34.2 \%)$ & $15(4.8 \%)$ & $9(2.9 \%)$ & \\
\hline 2 & $\begin{array}{l}\text { A woman should always have the right to have an } \\
\text { abortion in case of an unwanted pregnancy. }\end{array}$ & $27(8.7 \%)$ & $28(9.0 \%)$ & $25(8.1 \%)$ & $101(32.6 \%)$ & $129(41.6 \%)$ \\
\hline 3 & Legal induced abortion is equivalent to murder. & $27(8.7 \%)$ & $42(13.5 \%)$ & $54(17.4 \%)$ & $99(31.9 \%)$ & $88(28.4 \%)$ \\
\hline 4 & $\begin{array}{l}\text { Legalization of abortion allows youth to freely engage in } \\
\text { sexual activities. }\end{array}$ & $66(21.3 \%)$ & $60(19.4 \%)$ & $81(26.1 \%)$ & $70(22.6 \%)$ & $33(10.6 \%)$ \\
\hline 5 & $\begin{array}{l}\text { Legalization of abortion controls the population. } \\
\text { A woman needs to have her partner or spouse's consent }\end{array}$ & $5(1.6 \%)$ & $25(8.1 \%)$ & $29(9.4 \%)$ & $99(39.9 \%)$ & $152(49.0 \%)$ \\
\hline 7 & $\begin{array}{l}\text { Family planning method prevents unwanted pregnancy. } \\
\text { fo have an abortion. }\end{array}$ & $8(2.6 \%)$ & $15(4.8 \%)$ & $26(8.4 \%)$ & $131(42.3 \%)$ & $130(41.9 \%)$ \\
\hline 8 & $\begin{array}{l}\text { Abortions among unmarried women are acceptable in } \\
\text { case of unplanned pregnancy. }\end{array}$ & $36(11.6 \%)$ & $55(17.7 \%)$ & $82(26.5 \%)$ & $102(32.9 \%)$ & $35(11.3 \%)$ \\
\hline 9 & $\begin{array}{l}\text { Unmarried women have more complications from } \\
\text { abortions than married women. }\end{array}$ & $4(1.3 \%)$ & $22(7.1 \%)$ & $58(18.7 \%)$ & $134(43.2 \%)$ & $92(29.7 \%)$ \\
\hline 10 & $\begin{array}{l}\text { All women who undertake safe abortion will have } \\
\text { fertility problems in later life. }\end{array}$ & $34(11.0 \%)$ & $64(20.6 \%)$ & $71(22.9 \%)$ & $86(27.7 \%)$ & $55(17.7 \%)$ \\
\hline
\end{tabular}


Nirmala Ghimire et.al. Knowledge and attitude towards safe abortion among undergraduate students in Jana Bhawana Campus, Lalitpur, Nepal.

Majority 193(62.3\%) respondents had fair knowledge, 94(30.3\%) had low knowledge and only $23(7.4 \%)$ had high knowledge regarding safe abortion. The mean knowledge score was 13.6 with SD \pm 3.2 , Figure 1 .

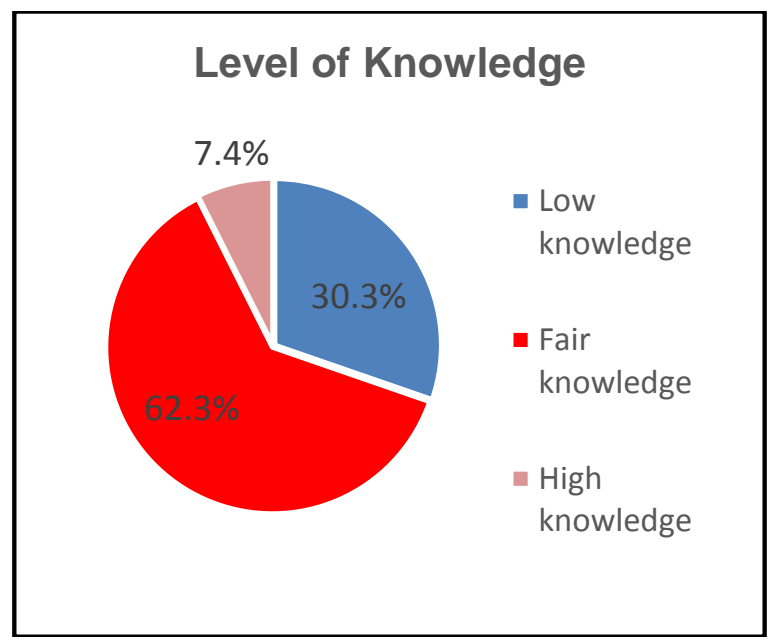

Figure 1: Respondents overall knowledge level on safe abortion

More than half of respondents $156(50.3 \%)$ had negative attitude, whereas $154(49.7 \%)$ respondents had positive attitude regarding safe abortion. The mean attitude score was 31.4 with SD \pm 4.1 , Figure 2.

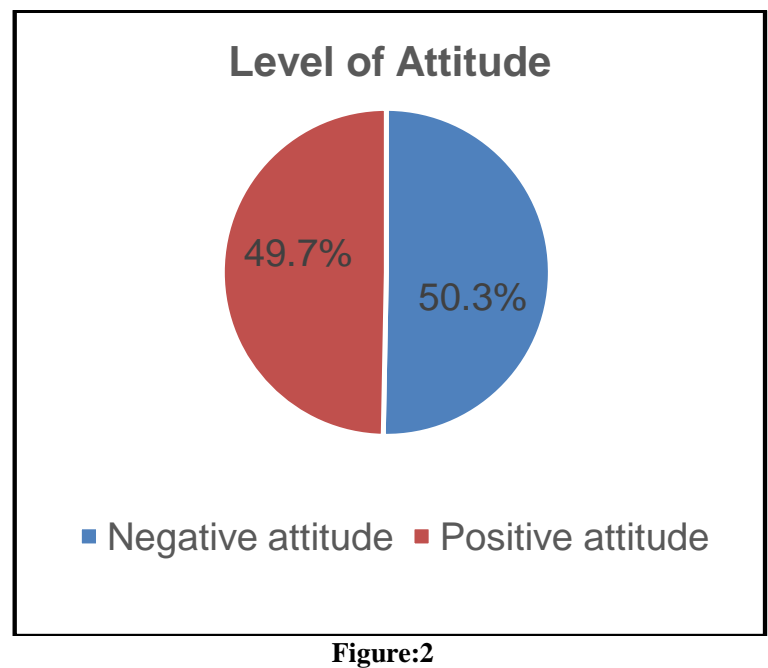

Age, gender, marital status, ethnicity, type of family, area of residence and living arrangement were not significantly associated with the knowledge on safe abortion among respondents, Table 4.

Table 4: Association between selected demographic variables and knowledge on safe abortion among respondents $(\mathrm{N}=310)$

\begin{tabular}{|c|c|c|c|c|c|}
\hline \multirow{2}{*}{ Demographic variables } & \multicolumn{2}{|c|}{ Knowledge on safe abortion } & \multirow[b]{2}{*}{ Total } & \multirow[b]{2}{*}{$\gamma^{2}$} & \multirow[b]{2}{*}{ p-value } \\
\hline & Poor knowledge & Good knowledge & & & \\
\hline \multicolumn{6}{|l|}{ Age } \\
\hline$>20$ years & 19 & 44 & 63 & .975 & .001 \\
\hline$\geq 20$ years & 75 & 172 & 247 & & \\
\hline \multicolumn{6}{|l|}{ Gender } \\
\hline Male & 42 & 95 & 137 & .909 & .013 \\
\hline Female & 52 & 121 & 173 & & \\
\hline \multicolumn{6}{|l|}{ Marital status } \\
\hline Unmarried & 88 & 186 & 274 & 3.595 & .058 \\
\hline Married & 6 & 30 & 36 & & \\
\hline \multicolumn{6}{|l|}{ Ethnicity } \\
\hline Brahmin/Chhetri & 48 & 120 & 168 & .532 & .466 \\
\hline Other caste & 46 & 96 & 142 & & \\
\hline \multicolumn{6}{|l|}{ Type of family } \\
\hline Single & 61 & 128 & 168 & .874 & .350 \\
\hline Joint & 33 & 88 & 121 & & \\
\hline \multicolumn{6}{|l|}{ Area of residence } \\
\hline Urban & 52 & 108 & 160 & .742 & .389 \\
\hline Rural & 42 & 108 & 150 & & \\
\hline \multicolumn{6}{|l|}{ Living arrangement } \\
\hline With family member & 82 & 184 & 266 & .226 & .635 \\
\hline With friends/alone & 12 & 32 & 44 & & \\
\hline
\end{tabular}

Note $=p \leq 0.05:$ Significant at $95 \%$ Confidence Interval

\section{DISCUSSION}

This study was carried out to find out the knowledge and attitude on safe abortion among undergraduate students. Our study found that there was no significant relationship with age, gender, marital status, ethnicity, type of family, area of residence and living arrangement with knowledge on safe abortion. This might be due to similarity in age and exposure to 
information. The finding of our study showed that majority 193(62.3\%) respondents had fair knowledge, 94(30.3\%) had low knowledge and only 23(7.4\%) had high knowledge regarding safe abortion. This finding was consistent with the study done in Pokhara, Nepal where 20(40\%) of respondents had high as well as fair level of knowledge on safe abortion and 10(20\%) of the respondents had low level of knowledge on safe abortion. ${ }^{[6]}$ The similarity in finding could be due to similarity in age group of respondents and most of the reproductive age group women gained knowledge about reproductive health in their school curriculum.

According to this study finding, nearly half $154(49.7 \%)$ respondents had positive attitude and $156(50.3 \%)$ had negative attitude towards safe abortion. Almost similar finding was noted in a study done in Gondar town, Ethiopia where 361 (57\%) respondents had positive attitude towards safe abortion. ${ }^{[8]}$ Consistent to this finding from another study done in Kebribayah town Ethiopia where $100(40.7 \%)$ of respondent had positive attitude towards safe abortion. ${ }^{[7]}$ Slight difference in result was found in the study done in Ethiopia among participants, 313 (74.17\%) had positive attitude towards safe abortion. ${ }^{[9]}$ Dissimilarities in result could be due to difference in study samples and geographical location.

The present study revealed that majority 230(74.2\%) respondents stated the correct meaning of safe abortion. This finding were supported with the studies done in Pokhara, Nepal and Bhaktpur Nepal where $90(100 \%)$ and 59(56.2\%) respectively correctly answered safe abortion as abortion done under legal condition. ${ }^{[10,11]}$ This study showed that all of respondents agreed that safe abortion services are necessary among reproductive age group 204(65.8\%) said safe abortion is necessary to save the life of mother. Difference in result is found in the study conducted in Ethiopia where 313(74.1\%) agreed its necessity and $79(25.23 \%)$ answered safe abortion is necessary to save the life of mother. ${ }^{[9]}$

In the present study, majority of respondents $270(87.1 \%)$ knew the legal status of abortion in Nepal. The result were consistent with studies done in Nepal among reproductive age women attending medical college and a study conducted in India among college going adolescent girls where $133(66.5 \%)$ and $52(73.3 \%)$ study participants were aware about legality of abortion respectively ${ }^{[12,13]}$. This finding is higher than a study conducted in Nepal using Nepal Demography and Health Survey 2011including youth aged 15-24 years. The study indicates that nearly half $2070(41 \%)$ youth were aware about the law. ${ }^{[14]}$ The difference in finding may be due to the reason that the study was limited among bachelor level students and study was conducted in an urban setting. The finding is also comparable in a study conducted in Ethiopia, where study revealed nearly three-fourths 452 (71.4\%)) of the respondents replied that Ethiopia has an abortion law. ${ }^{[8]}$ The similar result could be due to study was carried out among female college students and similar age group.

Similarly our study found that $190(61.3 \%)$ of respondents knew about legally allowed time for safe abortion i.e. up to 12 weeks of gestation. This finding is supported with the study conducted in Nepal among undergraduate students where, majority $75(83.30 \%)$ respondents had correct knowledge on legally allowed time for safe abortion. ${ }^{[10]}$ Another study also revealed the consistent finding where majority respondents $89(73.0 \%)$ had correct knowledge that a pregnant woman can terminate pregnancy on her own will up to 12 weeks of gestation. ${ }^{[15]}$ Regarding the especial condition that allowed for safe abortion, this study noted that among the respondents $195(62.9 \%)$ responded as when the life of woman or fetus are threatened followed by $163(52.6 \%)$ pregnancy resulted from incest or rape, 136(43.9\%) if woman has physical or mental disabilities and $111(35.8 \%)$ if fetus has severe 
abnormalities. Consistent result was found in a study carried out in Ethiopia, where $87(87 \%)$ respondents stated pregnancy as a result of rape or incest followed by $69(69 \%)$ when fetus or woman lives are endangered, $53(53 \%)$ when fetus has severe abnormalities and $45(45 \%)$ when a woman has physical or mental disabilities. ${ }^{[16]}$ Similarly, another study done in Ethiopia showed comparable result in which $(59 \%)$ of women, believed that abortion is legal if it has problem on mothers. ${ }^{[17]}$

In the present study, while asking the places for safe abortion services, the study found that majority $(84.2 \%)$ of the respondents reported that Government authorized hospitals are the best places. The result is comparable with a study done in Nepal which shows that most $88(97.80 \%)$ of the respondents mentioned that Government approved Hospitals/clinics are the best place for providing abortion services. ${ }^{[10]}$ This finding is also supported by a study done in Nepal where $84(68.9 \%)$ respondents stated that hospitals are the appropriate place for safe abortion. ${ }^{[15]} \mathrm{A}$ study done in Rajasthan, India among women who came for medical termination of pregnancy in a medical college revealed contradictory finding where $100(58 \%)$ of the respondents knew that safe abortions were performed at government approved institutions. ${ }^{[18]}$ The difference in findings could be due to difference in educational level and difference in samples.

The finding of this study also found that most of the respondents $269(86.8 \%)$ reported that trained health worker is needed to carry out safe abortion services. This finding is higher than a study performed among undergraduate students in Nepal, where nearly half $90(41.90 \%)$ respondents said that trained health care providers are required for safe abortion procedure. ${ }^{[10]}$ In contrast to this finding a study done in India showed that $38(38 \%)$ of respondent knew that safe abortion procedures should be done by trained doctors. ${ }^{[18]}$ The dissimilarities in the findings might be due to change in the time period and increase in the knowledge level with awareness through mass media like television, newspaper and online health message.

In the present study regarding the method of safe abortion, 192(61.9\%) of the respondents claimed that it can be done using medicine and 181(58.4\%) respondents reported that it can be done using instrument. This finding is supported by a study performed in Ethiopia, where $373(77.2 \%)$ of respondents reported medical abortion and 304(62.9\%) of respondents reported instrumental methods as method of abortion techniques. ${ }^{[8]}$

The study result further revealed that unsafe abortion can cause various complications among them like bleeding, death, infertility and infection, 228(73.5\%), $198(63.9 \%), \quad 162(52.3 \%)$ and $99(31.9 \%)$ respectively. This study result is slight higher than a study done among reproductive aged women in Nepal where complications of unsafe abortion are bleeding 60(57.1\%), death 34(32.4\%), infection $17(16.2 \%)$ and infertility $16(15.2 \%) .{ }^{[11]}$ The variation in result may be due to literacy level and variation in age group of participants.

A discrepancy was observed in a study conducted in Jharkhand, India where only half of the study subjects were aware about complications following abortion with most common being bleeding 33(46.5\%) followed by infection $20(28.2 \%)$ and death $2(2.8 \%)$. None of them knew that abortion can cause infertility too. [13] This discrepancy in the result might be due to difference in age of the respondents and only first year bachelor student were included in that study.

\section{CONCLUSION}

The findings from this study concluded that majority of the respondents had fair knowledge on safe abortion. Nearly half of the respondents had positive attitude towards safe abortion. The study further revealed that various demographic variables like age, gender, marital status, ethnicity, type of family, area of residence and living 
arrangement were not found to be associated with knowledge on safe abortion. Majority of the respondents knew the legal condition allowed for safe abortion. Most of the respondents claimed that the Government authorized hospitals are best places for safe abortion services.

Despite having fair level of knowledge among majority of respondents, it is seen that half of the respondents had negative attitude towards safe abortion. This shows that there is a need for educational intervention among undergraduate students in order to change their attitude.

Since this study is small scale study it cannot be generalized and since it was carried out in only one setting.

Instead of using self-administered questionnaire as a method of collecting data for assessing attitude, interview schedule could have been better as it could have explored respondents' views in a better way.

\section{ACKNOWLEDGEMENT}

The authors acknowledge all the participants who are involved in the study. Our special thanks go to Jana Bhawana Campus for granting permission to conduct the study.

\section{Conflict of Interest: None}

\section{Source of Funding: None}

\section{Ethical Approval: Approved}

\section{REFERENCES}

1. WHO. Preventing unsafe abortion: Key facts. 2019. Available from www.who.int > Health topics

2. World Health Organization. Preventing unsafe abortion. Geneva, Switzerland. 2019. Available from apps.who.int, iris , bitstream , handle , WHO-RHR-19.21eng.pdf

3. Yogi A, KC P, Neupane S. Prevalence and factors associated with abortion and unsafe abortion in Nepal: a nationwide crosssectional study. BMC Pregnancy Childbirth. 2018; 18 (376).
4. Ministry of Health, Nepal; New ERA, ICF. Nepal Demographic and Health Survey 2016. 2017. Kathmandu, Nepal.

5. Warriner IK, Shah IH, eds., Preventing Unsafe Abortion and its Consequences: Priorities for Research and Action. New York: Guttmacher Institute, 2006. Available from www.who.int > reproductivehealth , publications $>$ unsafe abortion

6. Acharya, Bhattarai. Assessment of the level of knowledge regarding safe abortion among reproductive age group women, a short cross sectional study in lekhnath, kaski. Journal of Institute of Medicine. 2017; 39(1): 105-109.

7. Dhar G. Knowledge, attitude and associated factors towards safe abortion among female students of kebribayah town of Somali region, Ethiopia. International Journal of Health Sciences \& Research. 2017; 7(10):176-185.

8. Mekonnen BD, Wubneh CA. Knowledge, Attitude, and Associated Factors towards Safe Abortion among Private College Female Students in Gondar City, Northwest Ethiopia: A Cross-Sectional Study. Advances in preventive medicine. 2020; 4(2020).

9. Mekuriaw S, Dereje RM, Kumalo A, Feyissa M. Knowledge, attitude and practice towards safe abortion among female students of Mizan-Tepi University, Southwest Ethiopia. Journal of Womens Health Care. 2015; 4(6):2167-420.

10. Ojha S, Silwal M. Knowledge and attitude on legalization of abortion among undergraduate students. Journal of Gandaki Medical College-Nepal. 2017; 10(2): 52-7.

11. Belbase M., \& Neupane J. (2018). Knowledge Regarding Legalization of Abortion among Women with Reproductive Age Group of Anantalingeshwor Municipality, Bhaktapur. EC Gynaecology. 2018; 7(11).

12. Tuladhar H, Risal A. Level of awareness about legalization of abortion in Nepal: a study at Nepal Medical College Teaching Hospital. Nepal Medical College Journal. 2010; 12(2):76-80.

13. Yasmin E, Kashyap V. Perceptions about abortion among college going late adolescent girls of Ranchi Women's College, Ranchi, Jharkhand - a pilot study. Journal of Medicine Sciences Public Health. 2019; 8(3):184-188. 
14. Adhikari R. Awareness of Liberalization of Abortion Law among Students in Nepal. Researchgate. 2017 May. Available from www.researchgate.net, publication > 318539187_Aware.

15. Khanal P, Sanjel K, Chalise HC. Knowledge and practice of abortion among women in Nepal. Asia-Pacific E-Journal of Health Social Science. 2014; 3(1):1-6.

16. Thomas G, Gedif T, Abeshu MA, Geleta B. Assessment of knowledge, attitude and practices regarding medication abortion among regular undergraduate female students in College of Social Sciences Addis Ababa University, Ethiopia. Adv Pharmacoepidemiol Drug Saf. 2016; 5(199): 2167-1052.

17. Debela TF, Mekuria MS. Knowledge and attitude of women towards the legalization of abortion in the selected town of Ethiopia: a cross sectional study. Reproductive health. 2018; 15(1):1-9.

18. Bamniya A, Verma S, The study of knowledge, attitude and practice about abortion and technology at the tertiary centre in the region of Mewar, Rajasthan, India. Int $\mathbf{J}$ Reprod Contracept Obstet Gynecology. 2018; 7(8)3320-4.

How to cite this article: Ghimire N, Nepal M, Shrestha $\mathrm{N}$ et.al. Knowledge and attitude towards safe abortion among undergraduate students in Jana Bhawana Campus, Lalitpur, Nepal. Int J Health Sci Res. 2021; 11(5): 269277. DOI: https://doi.org/10.52403/ijhsr. 20210543 